\title{
Awareness and practice of contraceptive methods among women in Kerala, India
}

\author{
Anila Tresa Alukal, Lissiamma George*, Resmy C. Raveendran
}

Department of Obstetrics and Gynecology, Government Medical College, Thrissur, Kerala, India

Received: 23 January 2018

Accepted: 28 February 2018

\section{*Correspondence:}

Dr. Lissiamma George,

E-mail: drlissiammag@gmail.com

Copyright: (c) the author(s), publisher and licensee Medip Academy. This is an open-access article distributed under the terms of the Creative Commons Attribution Non-Commercial License, which permits unrestricted non-commercial use, distribution, and reproduction in any medium, provided the original work is properly cited.

\begin{abstract}
Background: India is the second most populous country in the world, sustaining $17.01 \%$ of world population on $2.4 \%$ of world's surface area. Indian women have more children than desired and often too close together. Family Planning can have a positive impact on population growth, maternal mortality, and infant and new-born outcomes. In spite of availability of wide range of contraceptives, the unmet need for family planning is estimated to be $12.8 \%$. The purpose of this study is to assess awareness of the effective use of contraceptive methods among pregnant women, which will provide useful information for future intervention strategies and the reduction of unwanted pregnancies.

Methods: The study was conducted at the Government Medical College Thrissur, Kerala and study period was 1year (2014-2015). The awareness and contraceptive practices of 514 pregnant women who were admitted for delivery were assessed by using questionnaire. The data was entered in MS excel sheet and analysed using SPSS software.

Results: the awareness regarding barrier method of contraception was maximum. (96.7\%), followed by permanent methods (96.8\%), IUCD (94.9\%) and natural methods (92.6\%). Around $71.6 \%$ of the study population has used some form of contraception. The most commonly contraceptive method was natural methods $(69.6 \%)$ followed by barrier method (59.9\%). IUCD was the method which was least practiced $(2.9 \%)$ followed by OC pills $(19.1 \%)$.

Conclusions: Even though women are well aware of most of the contraceptive methods, the percentage of women using it is very low. This shows that there is good knowledge regarding contraceptive methods, but a change is needed in the attitude and practice.
\end{abstract}

Keywords: Awareness, Contraception, Family planning

\section{INTRODUCTION}

India is the second most populous country in the world, and accounts for more than $20 \%$ of global maternal and child deaths - most of them preventable. ${ }^{1}$ Indian women have more children than desired and often too close together. Family Planning can have a positive impact on population growth, maternal mortality, and infant and new-born outcomes. ${ }^{2}$

In spite of availability of wide range of contraceptives, the unmet need for family planning is estimated to be $12.8 \% .^{3}$ By limiting births, preventing closely spaced births or births to very young or old mothers, neonatal and infant, child and maternal mortality can be reduced. ${ }^{4}$ Family planning can avert more than $30 \%$ of maternal deaths and $10 \%$ of child mortality if couples spaced their pregnancies more than 2 years apart. In 1951, India was the world's first nation where the government launched a Family Planning Programme. ${ }^{5}$

Over the years India's family planning programme has evolved with the shift in focus from merely population control to more critical issues of saving the lives and improving the health of mothers and newborns. ${ }^{6}$ Ensuring healthy timing and spacing of pregnancies is the most 
important intervention for reproductive, maternal, neonatal, child and adolescent health. There is renewed emphasis on spacing methods of family planning. ${ }^{7}$ Use of reversible and spacing methods of contraceptives can save women's lives and health due to a reduction in unwanted, closely spaced and mistimed pregnancies and thus avoiding pregnancies with higher risks and chances of abortions, which may be unsafe. ${ }^{8}$

Increased institutional deliveries in India provides an opportune time for offering family planning services to the women, who have just delivered at health facilities and want to prevent unintended pregnancies or delay having more children. ${ }^{8}$ Moreover, unmet need for family planning is very high in the postpartum period ${ }^{9}$. Approximately $27 \%$ of births in India occur less than 24 months after a previous birth. Another $34 \%$ of births occur between 24 and 35 months. $61 \%$ of births in India occur at intervals that are shorter than the recommended birth-to-birth interval of approximately 36 months (3 years)..$^{10}$

\section{METHODS}

The study was an observational study looking at awareness and practice of contraceptive methods in pregnant women. It was conducted at the Government Medical College Thrissur, Kerala, a tertiary referral centre for a duration of 1 year, from February 2014 to January 2015, after getting clearance from Institutional Research Committee and ethical committee. The study population included women delivered at Government Medical College, Thrissur during the study period including both vaginal and caesarean section. Sample size was 514. Interviewer administered structured questionnaire was filled up to assess the awareness and practice of various family planning methods and also the prior use of contraceptive methods of 514 pregnant women who were admitted for delivery at Govt. Medical College, Thrissur. Data was coded and entered in MS Excel and analysed using SPSS software.

\section{RESULTS}

Most of the subjects (78.3\%) of the study belonged to the age group of 21-30. Most subjects of the study population had completed high school education (74.2\%) showing that the literacy rate in Kerala is high.

Table 1: Frequency distribution of age among the study population.

\begin{tabular}{|c|c|c|}
\hline Age group & Frequency & Percent \\
\hline Less than 20 & 43 & 8.4 \\
\hline $21-30$ & 403 & 78.4 \\
\hline $31-40$ & 64 & 12.5 \\
\hline More than 40 & 4 & .8 \\
\hline Total & 514 & 100.0 \\
\hline
\end{tabular}

Majority (67.6\%) of the study population were housewives. Only $32.2 \%$ had some form of employment. Most of the study population belonged to multigravida group $(66.2 \%)$.

Table 2: Frequency distribution of educational status of the study population.

\begin{tabular}{|lll|}
\hline Education & Frequency & Percent \\
\hline Nil & 6 & 1.2 \\
\hline Primary & 59 & 11.5 \\
\hline 10th pass & 382 & 74.3 \\
\hline Graduate & 67 & 13.0 \\
\hline Total & 514 & 100.0 \\
\hline
\end{tabular}

Around $28.9 \%$ of the study population had last child birth within 3 years, $37.3 \%$ had last child birth 3 or more years earlier and $33.6 \%$ were primigravida. $92.6 \%$ of the study population had awareness of natural methods of contraception.

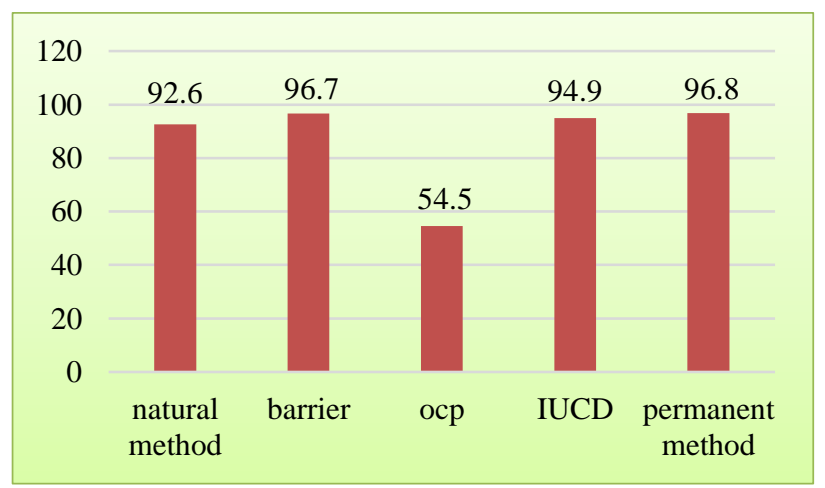

Figure 1: Frequency distribution of awareness of contraceptive methods.

96.7\% women were aware of barrier contraception. $96.8 \%$ women of the study population were aware of permanent methods of sterilisation. $71.6 \%$ of the women of study population gave history of prior use of some form of contraceptive method.

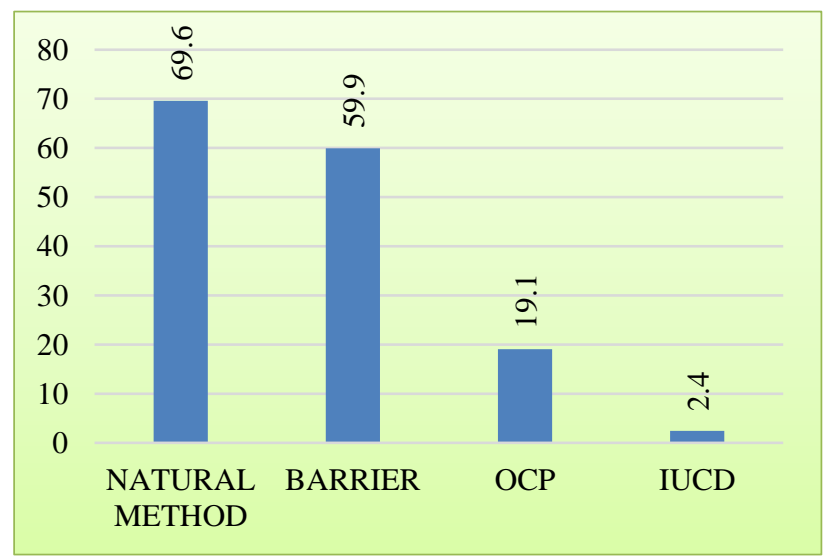

Figure 2: Frequency distribution of prior use of contraception 
$69.6 \%$ of the study population gave history of use of natural methods of contraception. $59.9 \%$ women of the study population gave history of use of barrier contraception. Only $19.1 \%$ of the study population have used Oral contraceptive pills for contraception. Only $2.1 \%$ of the study population have used Intrauterine Contraceptive Device in the past. Only $27.4 \%$ of the study population had a planned pregnancy.

\section{DISCUSSION}

In the present study the awareness and contraceptive practices of 514 patients were assessed. The mean age of the study population was 26.12 .

In the present study majority of the study population had passed tenth standard $87.3 \%$. Only 6 out of 514 (1.2) had no schooling.

Around $13 \%$ were graduates. In a similar study by Srivastav et al in Kanpur, most of the study subjects had high school and intermediate school education which is comparable to the present study. ${ }^{11} 71.22 \%$ were aware of at least oneof family planning methods which is less when compared to our study population.

In a similar study conducted by Budi et al in Indonesia, $86.53 \%$ of pregnant women were aware of contraceptive methods whereas in our study $97 \%$ of the pregnant women were aware of contraceptive methods. ${ }^{12}$ The best known temporary method in the present study was barrier contraception $(96.7 \%)$. But the best-known method in their study was injection $(63.97 \%)$.

In another study conducted in Nepal, by Tuladhar et al, $93.0 \%$ of the study population were aware of at least one of family planning methods, compared to $97 \%$ in the present study. ${ }^{13}$

In the study by Tuladhar etal, only $65.0 \%$ had prior usage of contraceptive method. Whereas in the present study $71.6 \%$ gave history of prior use of contraception. ${ }^{13}$ This shows the slightly better acceptance of our population towards contraceptive methods.

In study by Tuladhar et al, the best-known method of temporary contraception was depot Provera (78.0\%) followed by oral contraceptive pills $(74.0 \%)$ and condom $(71.0 \%)$. The best known temporary method in the present study was barrier contraception $(96.7 \%) .{ }^{13}$

In a similar study by Srivastav et al in Kanpur, the bestknown method of contraception was condoms (88.78\%) followed by IUCD $(77.07 \%)$ and OCP $(72.19 \%){ }^{11}$

This shows the regional differences in awareness of various contraceptive methods. This also implies the role played by media in popularising various contraceptive methods.
In the study by Tuladhar et al in Nepal, regarding prioruse of contraception depot Provera (11.0\%) was the most widely used followed by oral contraceptive pills $(4.5 \%)$ and condom (4.5\%). ${ }^{13}$ In the present study the most commonly practiced method was natural methods of contraception (69.6\%) followed by barrier contraception $(59.9 \%)$, Oral contraceptive pills $(19.1 \%)$, Intrauterine contraceptive device $(2.1 \%)$

\section{CONCLUSION}

Even though women are well aware of most of the contraceptive methods, the percentage of women using it is very low. This shows that there is good knowledge regarding contraceptive methods, but a change is needed in the attitude and practice. The stigma related to contraceptive methods like IUCD and oral contraceptive pills which are highly effective temporary methods can be removed only by effort of health system and health care workers. This in turn will help to reduce unwanted pregnancies as well as abortions, maternal and neonatal morbidity and mortality.

\section{ACKNOWLEDGMENTS}

Authors express heartfelt thanks to Department of Obstetrics and Gynaecology, Thrissur, for their cooperation extended throughout this study. Authors thankfully remember all the patients who trusted authors and were central to materialising this study.

Funding: No funding sources

Conflict of interest: None declared

Ethical approval: The study was approved by the Institutional Ethics Committee

\section{REFERENCES}

1. Rakhi J, Sumathi M. Contraceptive method: needs, options and utilization. J Obstet Gynecol India. 2011;61(6):626-34.

2. Upadhayay A, Shah SK, Thapa DK, Sanal TS, Ghimire R, Dahal HR. Knowledge, attitude and practice of family planning method among married women of reproductive age group in earth quake displaced population of Sindupalchok District, Nepal. Am J Pub Health Res. 2017;5(1):1-5.

3. Ghike S, Joshi S, Bhalerao A, Kawthalkar A. Awareness and contraception practices among women an indian rural experience. J South Asian Federation Obstet Gynecol. 2010;2(1):19-21.

4. Mehata S, Paudel YR, Dotel BR. Inequalities in the use of family planning in rural Nepal. Bio Med Res Int. 2014;2014.

5. Shweta SMB. Knowledge and pattern of family planning adoption Kashi Vidyapeet Block, Varanasi Dist (UP). Indian J Prev Soc Med. 2010;41:21-7.

6. Sunita TH, Desai RM. Knowledge, attitude and practice of contraception among women attending a 
tertiary care hospital in India. Int $\mathbf{J}$ Reprod Contracept Obstet Gynecol. 2013;2(2):172-6.

7. Sreytouch V. Knowledge, attitude and practice of family planning among women in Banteay Meanchey, Cambodia. 2010;27:103-15.

8. Brair SL, Eltayeb LB. Barriers to family planning service utilization among Sudanese women in Khartoum locality. Al Neelain Med J. 2012;3.

9. Ebrahim S, Muhammed N. Knowledge, attitude and practice of family planning among women in Basrah city South of Iraq. MBU. 2011;29(1,2):70-6.

10. Renjhen P, Kumar A, Pattanshetty S, Sagir A, Samarasinghe CM. A study on knowledge, attitude and practice of Contraception among college students in Sikkim. India. J Turkish-German Gynecol Assoc. 2010;11:78-81.

11. Srivastav A, Khan MS, Chauhan CR. Knowledge, attitude and practices about contraceptive among married reproductive females. Int J Sci Study. 2014;1(5):2-4.

12. Santoso BI, Surya R. Knowledge, attitude, and practice of contraception among pregnant women in Ende districet, east Nusa Tennaggara, Indonesia. J South Asian Feder Obst Gynae. 2017;9(2):110-8.

13. Tuladhar H, Marahatta R. Awareness and practice of family planning methods in women attending gyne OPD at Nepal medical college teaching hospital. Nepal Med Coll J. 2008;10(3):184-91.

Cite this article as: Alukal AT, George L,

Raveendran RC. Awareness and practice of contraceptive methods among women in Kerala, India. Int J Reprod Contracept Obstet Gynecol 2018;7:1501-4. 